\title{
A comparison between laser interferometric measurement of fundus pulsation and pneumotonometric measurement of pulsatile ocular blood flow
}

\section{Effects of changes in $\mathrm{pCO}_{2}$ and $\mathrm{pO}_{2}$ and of isoproterenol}

\section{Schmetterer \\ S. Dallinger \\ U. Graselli \\ H.-G. Eichler \\ M. Wolzt \\ Department of Clinical \\ Pharmacology \\ University of Vienna \\ Vienna, Austria}

\section{Schmetterer}

Institute of Medical Physics University of Vienna

Vienna, Austria

\section{O. Findl}

Department of Ophthalmology University of Vienna Vienna, Austria

Leopold Schmetterer, PhD $\rightarrow$

Department of Clinical Pharmacology Währinger Guertel 18-20 A-1090 Vienna, Austria

Tel: +43140400/2981 Fax: +43 1 40400/2998 e-mail: Leopold.Schmetterer@ univie.ac.at

Received: 24 May 1999 Accepted without revision: 15 September 1999

\section{Abstract}

Purpose We have shown in the companion paper that, under baseline conditions, there is a high degree of association between laser interferometrically measured fundus pulsation amplitude (FPA) and

pneumotonometrically measured pulse amplitude (PA) and pulsatile ocular blood flow (POBF). The present study investigated the effect of high $\mathrm{pCO}_{2}$, of high $\mathrm{pO}_{2}$ and of isoproterenol on POBF as assessed with laser interferometry and pneumotonometry. Methods Pneumotonometry and laser interferometry were performed in young healthy subjects during breathing of $100 \% \mathrm{O}_{2}$ ( $n=10$; hyperoxia) and of $5 \% \mathrm{CO}_{2}+95 \%$ air ( $n=8$; hypercapnia). In addition these parameters were studied during stepwise increasing doses of isoproterenol, a $\beta$-receptor agonist $(n=8)$.

Results Inhalation of $5 \% \mathrm{CO}_{2}+95 \%$ air increased FPA $(24 \pm 12 \%, p<0.001)$, PA $(26 \pm 13 \%, p<0.001)$ and POBF (15 $\pm 8 \%$, $p=0.002)$. Inhalation of $100 \% \mathrm{O}_{2}$ decreased FPA $(-5 \pm 7 \%, p=0.027)$, but did not change PA or POBF. The effect of $100 \% \mathrm{O}_{2}$ inhalation on FPA in the optic disc was more pronounced $(-11 \%$ to $-20 \%)$ than in the macula. Isoproterenol caused a dose-dependent increase in FPA, PA and POBF $(p<0.001)$. The association between the induced changes in FPA and PA or POBF was highly significant. Conclusions The present study shows that FPA can be taken as a valid relative measure of pulsatile choroidal blood flow. Our results in
LEOPOLD SCHMETTERER, SUSANNE DALLINGER, OLIVER FINDL,

URSULA GRASELLI, HANS-GEORG EICHLER, MICHAEL WOLZT the optic disc indicate that FPA at the neuroretinal rim and the cup is influenced by retinal and choroidal circulation.

Key words Fundus pulsation, Ocular blood flow, Pneumotonometry

The validity of new methods for regional blood flow measurement is normally tested by comparison with a criterion standard. However, no generally accepted standard method exists for the assessment of choroidal perfusion. An excellent overview of the limitations of currently available techniques has recently been published by Kiel. ${ }^{1}$ Hence novel approaches can only be validated on the basis of comparison between methods and investigations on the sensitivity to detect changes in choroidal blood flow.

We have recently introduced a new method for the investigation of choroidal blood flow in humans, which measures distance changes between cornea and retina during the cardiac cycle. ${ }^{2}$ Our previous results indicate that this method is able to detect small changes in pulsatile choroidal blood flow. Namely, we have shown a dose-dependent increase in fundus pulsation during stepwise increasing doses of isoproterenol ${ }^{3}$ and a strong dependence of fundus pulsation on arterial carbon dioxide tension $\left(\mathrm{pCO}_{2}\right) .{ }^{4,5}$

In the companion paper ${ }^{6}$ we have shown that there is a high association between laser interferometrically measured fundus pulsation and pneumotonometrically measured pulse 
amplitude (PA) and pulsatile ocular blood flow (POBF). The present investigations studied the effect of different pharmacological stimuli on the pulsatile component of ocular blood flow as assessed with pneumotonometry and laser interferometry. Whereas the investigations presented in the companion paper focused on the correlation between subjects under baseline conditions, the present studies were designed to characterise the within-subject correlation during perturbations.

\section{Methods \\ Subjects}

The study protocols were approved by the Ethics Committee of Vienna University School of Medicine. The studies were performed in male and female non-smoking subjects, aged between 19 and 35 years (studies A, D and E: $n=8$; studies B and C: $n=10$ ). All participating subjects were informed of the nature of the study and signed a written consent. Each subject passed a screening examination that included medical history and physical examination, and 12-lead electrocardiogram. Subjects were excluded if any abnormality was found as part of the pretreatment screening. Additionally, an ophthalmic examination was performed in each subject prior to the study day. Inclusion criteria were normal ophthalmic findings, ametropia of less than 3 dioptres, and an ametropia difference between the two eyes of less than 1 dioptre. In all subjects the right eye was studied.

\section{Experiment design}

\section{Study A}

The effect of breathing $5 \% \mathrm{CO}_{2}+95 \%$ air on ocular haemodynamic parameters was investigated. Fundus pulsation amplitude (FPA) in the macula, PA, POBF, systemic blood pressure, pulse rate and blood gases were measured at baseline and after $10 \mathrm{~min}$ of inhalation.

\section{Study B}

In another study the effect of $5 \% \mathrm{CO}_{2}+95 \%$ air breathing on regional FPA was assessed. FPA was measured at five preselected retinal points from $10^{\circ}$ temporal to $10^{\circ}$ nasal to the macula along the $0^{\circ}$ meridian. FPA, systemic haemodynamics and blood gases were measured at baseline and after $10 \mathrm{~min}$ of inhalation.

\section{Study C}

Additionally we investigated the effect of $100 \% \mathrm{O}_{2}$ breathing on ocular haemodynamic parameters. FPA in the macula, PA, POBF, systemic blood pressure, pulse rate and blood gases were measured at baseline and after $10 \mathrm{~min}$ of inhalation.
Study D

The effect of $100 \% \mathrm{O}_{2}$ inhalation was also investigated on FPA in the optic disc. Measurements were performed at points 1, 3, 5 and 7 as defined in the companion paper. ${ }^{6}$ Points 1 and 3 were located at the neuroretinal rim, points 5 and 7 at the cup. FPAs, systemic haemodynamics and blood gases were measured at baseline and after $10 \mathrm{~min}$ of inhalation.

\section{Study E}

One study was performed to investigate the haemodynamic effects of isoproterenol, a non-specific $\beta$-adrenoceptor agonist. A 20G plastic cannula (Venflon, Viggo-Spectramed, Helsingborg, Sweden) was inserted into an antecubital vein. Subjects received infusions of stepwise increasing doses of isoproterenol (Isuprel, Winthrop Breon Laboratories, New York, NY; doses 0.05, $0.1,0.2,0.4,0.8 \mu \mathrm{g} / \mathrm{min})$. Infusion period was $10 \mathrm{~min}$ per infusion step. Measurements of fundus pulsations, PA, POBF, blood gases and systemic haemodynamics were performed in the last 5 min of each infusion step. Pulse rate and a real-time electrocardiogram were monitored continuously during the study period.

\section{Fundus pulsation measurements and pneumotonometric measurement of pulsatile ocular blood flow}

These methods are described in detail in the companion paper. ${ }^{6}$ The investigator who assessed the fundus pulsation measurements was masked to the intervention and to the results of pneumotonometry.

\section{Non-invasive measurement of systemic haemodynamics}

Systolic and diastolic blood pressure (SBP, DBP) were measured on the upper arm by an automated oscillometric device. Pulse pressure amplitude (PPA) was calculated as SBP-DBP, mean arterial pressure (MAP) was calculated as $1 / 3 \mathrm{SBP}+2 / 3 \mathrm{DBP}$. Pulse rate (PR) was automatically recorded from a finger pulseoximetric device (HP-CMS patient monitor, Hewlett Packard, Palo Alto, CA).

\section{Gas delivery and blood gas analysis}

All gases were delivered through a partially expanded reservoir bag at atmospheric pressure under nasal occlusion. Blood gas values were determined from arterialised capillary blood samples of the earlobe. After spreading the earlobe with nicotinate plus nonylvanillamid ointment (Finalgon, Thomae, Biberach, Germany) to induce capillary vasodilation a lancet incision was made. The blood was drawn into a glass capillary. Arterial $\mathrm{pH}, \mathrm{pCO}_{2}$ and $\mathrm{pO}_{2}$ were determined with an automatic blood gas analysis system (AVL 995-Hb, Graz, Austria). 


\section{Data analysis}

To correct for heart rate changes during isoproterenol infusion we calculated a corrected fundus pulsation amplitude as FPAC $=\mathrm{FPA} \times[\mathrm{PR}($ iso $) / \mathrm{PR}($ bas $)]$. In this equation $\mathrm{PR}$ (iso) is the pulse rate during isoproterenol infusion and PR(bas) is the pulse rate during baseline conditions. The association between the percentage changes in FPA, FPAC, PA and POBF induced by changes in $\mathrm{CO}_{2}$ and isoproterenol was calculated by linear regression. The effect of $5 \% \mathrm{CO}_{2}+95 \%$ air inhalation and $100 \% \mathrm{O}_{2}$ inhalation from baseline was assessed by paired $t$-tests. The effect of isoproterenol was assessed by repeated measures ANOVA. Data are presented as the mean $\pm \mathrm{SD}$. A $p$ value $<0.05$ was considered significant.

\section{Results}

Effects of high $p \mathrm{CO}_{2}$

Study A

Baseline value for FPA was $3.5 \pm 1.2 \mu \mathrm{m}$, for PA $2.4 \pm 0.4 \mathrm{mmHg}$ and for POBF $924 \pm 158 \mu \mathrm{l} / \mathrm{min}$. The association between individual hypercapnia-induced changes in FPA and pnemotonometric parameters is depicted in Fig. 1. The association was significant between FPA and PA, but did not reach significance between FPA and POBF. Inhalation of $5 \% \mathrm{CO}_{2}+95 \%$ air produced a $24 \pm 12 \%$ increase in FPA $(p<0.001)$, a $26 \pm 13 \%$ increase in PA $(p<0.001)$ and a $15 \pm 8 \%$ increase in POBF $(p=0.002)$. As expected we observed an increase in $\mathrm{pCO}_{2}$ from $37.8 \pm 2.4 \mathrm{mmHg}$ to $46.9 \pm 2.4$ $\mathrm{mmHg}$ during inhalation $(p<0.001)$. Additionally,

Correlation: $r=0.68, p=0.064$

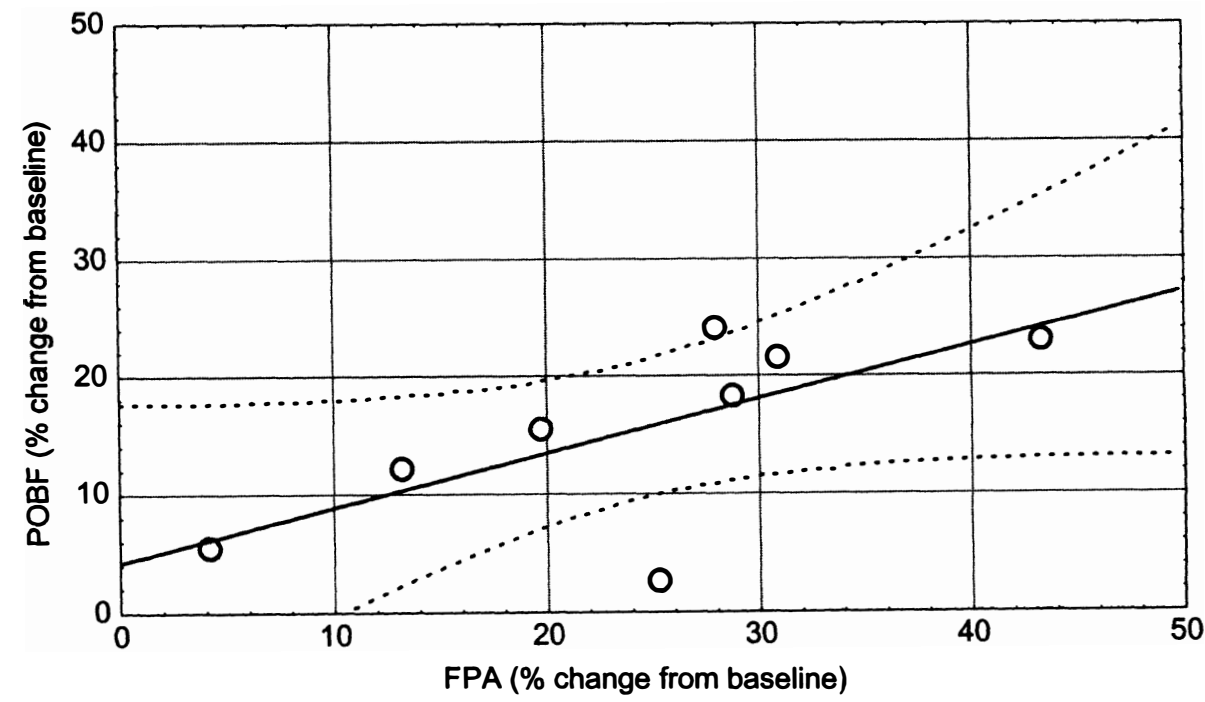

(a)

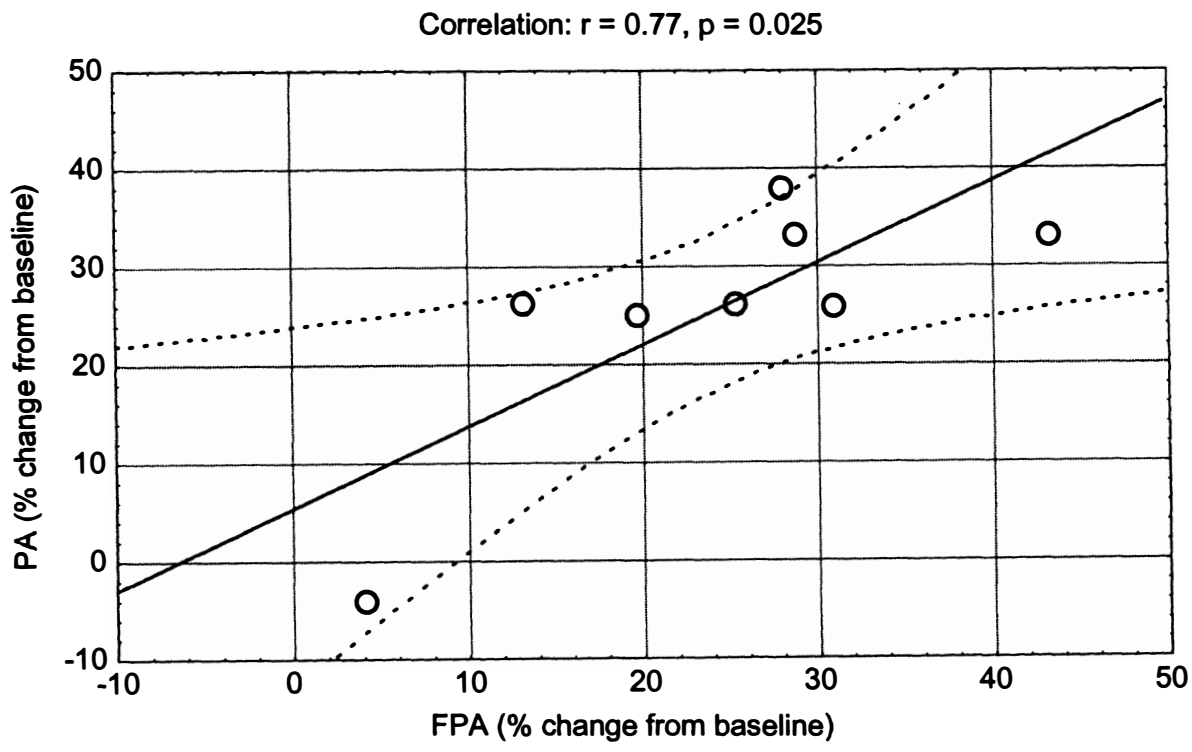

(b)

Fig. 1. Linear correlation $(\mathrm{n}=8)$ between individual hypercapnia-induced changes in fundus pulsation amplitude $(F P A)$ and the pulse amplitude (PA, lower panel) and fundus pulsation amplitude (FPA) and pulsatile ocular blood flow (POBF, upper panel). The regression lines and the $95 \%$ confidence intervals are shown. 
Table 1. Fundus pulsation amplitude on the retina $(\mu m)$ at baseline $(B L)$ and during $5 \% \mathrm{CO}_{2}+95 \%$ air breathing $(\mathrm{HC})$

\begin{tabular}{|c|c|c|c|c|c|c|c|c|c|c|}
\hline \multirow[b]{2}{*}{ Subject no. } & \multicolumn{2}{|c|}{$0^{\circ}$ (macula) } & \multicolumn{2}{|c|}{$10^{\circ}$ nasal } & \multicolumn{2}{|c|}{$5^{\circ}$ nasal } & \multicolumn{2}{|c|}{$5^{\circ}$ temporal } & \multicolumn{2}{|c|}{$10^{\circ}$ temporal } \\
\hline & $\mathrm{BL}$ & $\mathrm{HC}$ & BL & $\mathrm{HC}$ & BL & $\mathrm{HC}$ & $\mathrm{BL}$ & $\mathrm{HC}$ & $\mathrm{BL}$ & $\mathrm{HC}$ \\
\hline 1 & 5.0 & 6.5 & 4.1 & 5.3 & 4.0 & 5.6 & 4.3 & 5.5 & 4.0 & 5.8 \\
\hline 2 & 4.1 & 4.8 & 3.0 & 3.9 & 3.3 & 3.9 & 3.7 & 4.0 & 3.1 & 4.0 \\
\hline 3 & 4.5 & 4.6 & 4.0 & 4.3 & 4.3 & 4.1 & 4.0 & 4.4 & 4.5 & 4.9 \\
\hline 4 & 3.0 & 3.6 & 2.6 & 3.4 & 2.5 & 3.3 & 2.3 & 3.0 & 2.2 & 3.0 \\
\hline 5 & 2.2 & 2.9 & 2.0 & 2.6 & 2.1 & 3.0 & 1.9 & 2.5 & 2.1 & 2.6 \\
\hline 6 & 3.1 & 3.7 & 3.0 & 3.8 & 2.6 & 3.3 & 2.7 & 3.3 & 3.4 & 3.7 \\
\hline 7 & 3.0 & 3.8 & 2.3 & 3.0 & 2.4 & 3.3 & 2.4 & 3.0 & 2.5 & 3.2 \\
\hline 8 & 4.0 & 4.5 & 3.0 & 3.7 & 3.0 & 3.6 & 3.1 & 3.8 & 3.0 & 3.9 \\
\hline 9 & 2.0 & 2.5 & 1.5 & 1.7 & 1.5 & 1.9 & 1.6 & 2.1 & 1.9 & 2.0 \\
\hline 10 & 5.8 & 6.9 & 4.5 & 5.7 & 4.8 & 6.0 & 4.7 & 5.9 & 4.5 & 5.9 \\
\hline Total mean of 10 subjects & 3.7 & 4.4 & 3.0 & 3.7 & 3.1 & 3.8 & 3.1 & 3.8 & 3.1 & 3.9 \\
\hline
\end{tabular}

inhalation of $5 \% \mathrm{CO}_{2}$ with $95 \%$ air resulted in a slight increase in $\mathrm{pO}_{2}$ (from $99 \pm 11 \mathrm{mmHg}$ to $115 \pm 5 \mathrm{mmHg}$, $p=0.010$ ) and a decrease in $\mathrm{pH}$ (from $7.40 \pm 0.03$ to $7.33 \pm 0.02, p<0.001)$. Systemic haemodynamics were not altered by hypercapnia (data not shown).

\section{Study B}

The effect of hypercapnia on FPA at five different locations at the retina is presented in Table 1. Hypercapnia produced a significant increase in FPA at all fundus locations under study. This increase was $20 \pm 9 \%$ in the macula, $25 \pm 8 \%$ at $10^{\circ}$ nasal, $26 \pm 14 \%$ at $5^{\circ}$ nasal, $23 \pm 8 \%$ at $10^{\circ}$ temporal and $24 \pm 13 \%$ at $5^{\circ}$ temporal ( $p<0.001$ each). Again, inhalation of $5 \% \mathrm{CO}_{2}+$ $95 \%$ air produced a significant increase in $\mathrm{pCO}_{2}$ from $37.7 \pm 1.0 \mathrm{mmHg}$ to $47.2 \pm 1.1 \mathrm{mmHg}(p<0.001)$, in $\mathrm{pO}_{2}$ from $97 \pm 8 \mathrm{mmHg}$ to $107 \pm 12 \mathrm{mmHg}(p=0.020)$ and a decrease in $\mathrm{pH}$ from $7.40 \pm 0.02$ to $7.31 \pm 0.03(p<0.001)$. Systemic haemodynamics were not altered by hypercapnia (data not shown).

\section{Effects of high $\mathrm{pO}_{2}$}

Study C

Hyperoxia produced a small, but significant decrease in FPA in the macula from $3.7 \pm 1.2 \mu \mathrm{m}$ at baseline to $3.5 \pm 1.1 \mu \mathrm{m}(-5 \pm 7 \%, p=0.027)$. By contrast, the induced changes in PA (from $2.4 \pm 0.4 \mathrm{mmHg}$ to $2.3 \pm 0.4 \mathrm{mmHg},-3 \pm 7 \%$ ) and POBF (from

$909 \pm 148 \mu \mathrm{l} / \mathrm{min}$ to $904 \pm 148 \mu \mathrm{l} / \mathrm{min},-1 \pm 2 \%$ ) were not significant. Inhalation of $100 \% \mathrm{O}_{2}$ increased $\mathrm{pO}_{2}$ from $96 \pm 9 \mathrm{mmHg}$ to $471 \pm 45 \mathrm{mmHg}(p<0.001)$ and $\mathrm{pH}$ from $7.40 \pm 0.04$ to $7.43 \pm 0.03(p=0.043)$, but did not change $\mathrm{pCO}_{2}$. Systemic haemodynamics were not altered by hyperoxia (data not shown).

\section{Study D}

Breathing $100 \% \mathrm{O}_{2}$ decreased FPA at all measurement sites in the optic disc (Table 2). The reactivity at the neuroretinal rim (point 1: $-11 \pm 9 \%, p=0.018$; point 3: $-13 \pm 11 \%, p=0.009$ ) was lower than at the cup (point 5 : $-15 \pm 6 \%, p=0,004$; point 7: $-20 \pm 7 \%, p=0.027$ ). Again, we observed an increase in $\mathrm{pO}_{2}$ (from $98 \pm 8 \mathrm{mmHg}$ to $465 \pm 54 \mathrm{mmHg}, p<0.001$ ), but not in $\mathrm{pH}$ and $\mathrm{pCO}_{2}$. Systemic haemodynamics were not altered by hyperoxia (data not shown).

\section{Effects of isoproterenol}

Isoproterenol caused a dose-dependent increase in FPA $(p<0.001$, maximum effect: $31 \pm 10 \%)$, PA $(p<0.001$, maximum effect: $26 \pm 8 \%), \operatorname{POBF}(p<0.001$, maximum effect: $41 \pm 13 \%)$ and FPAC ( $p<0.001$, maximum effect: $43 \pm 6 \%$ ). We observed a high degree of association between isoproterenol-induced changes in FPA and POBF (Fig. 2; \%change in $\mathrm{POBF}=1.51+1.36 \times \%$ change in FPA), but the regression line was significantly steeper than the $45^{\circ}$ line $(p=0.012)$. The correlation between FPA and PA ( $\%$ change in PA $=-4.03+0.67 \times \%$ change in FPA) was also significant with a regression line flatter

Table 2. Fundus pulsation amplitude in the optic disc ( $\mu \mathrm{m})$ as calculated from five cardiac cycles at baseline (BL) and during $100 \% \mathrm{O}_{2}$ breathing (HO)

\begin{tabular}{|c|c|c|c|c|c|c|c|c|}
\hline \multirow[b]{2}{*}{ Subject no. } & \multicolumn{4}{|c|}{ Sites at the neuroretinal rim } & \multicolumn{4}{|c|}{ Sites at the cup } \\
\hline & $\mathrm{BL}$ & $\mathrm{HO}$ & $\mathrm{BL}$ & $\mathrm{HO}$ & $\mathrm{BL}$ & $\mathrm{HO}$ & $\mathrm{BL}$ & $\mathrm{HO}$ \\
\hline 1 & 7.4 & 6.5 & 6.8 & 6.0 & 9.1 & 7.4 & 9.9 & 7.3 \\
\hline 2 & 5.7 & 5.6 & 5.1 & 5.3 & 8.8 & 8.2 & - & - \\
\hline 3 & 7.8 & 6.0 & 7.5 & 5.8 & 6.3 & 5.3 & 7.8 & 7.0 \\
\hline 4 & 8.9 & 8.0 & 7.6 & 6.1 & 9.3 & 8.0 & 8.2 & 6.5 \\
\hline 5 & 7.0 & 6.0 & - & - & 9.1 & 6.8 & - & - \\
\hline 6 & - & - & 6.9 & 5.0 & - & - & - & - \\
\hline 7 & 8.0 & 6.4 & 7.3 & 7.1 & 6.8 & 6.0 & - & - \\
\hline 8 & 8.7 & 8.9 & 11.5 & 10.0 & - & - & 13.4 & 10.2 \\
\hline Total mean & 7.6 & 6.7 & 7.5 & 6.5 & 8.2 & 7.0 & 9.8 & 7.8 \\
\hline
\end{tabular}

Measurement sites are defined in the companion paper. ${ }^{6}$ At some measurement sites we did not obtain technically adequate interferograms for the evaluation of FPA. 


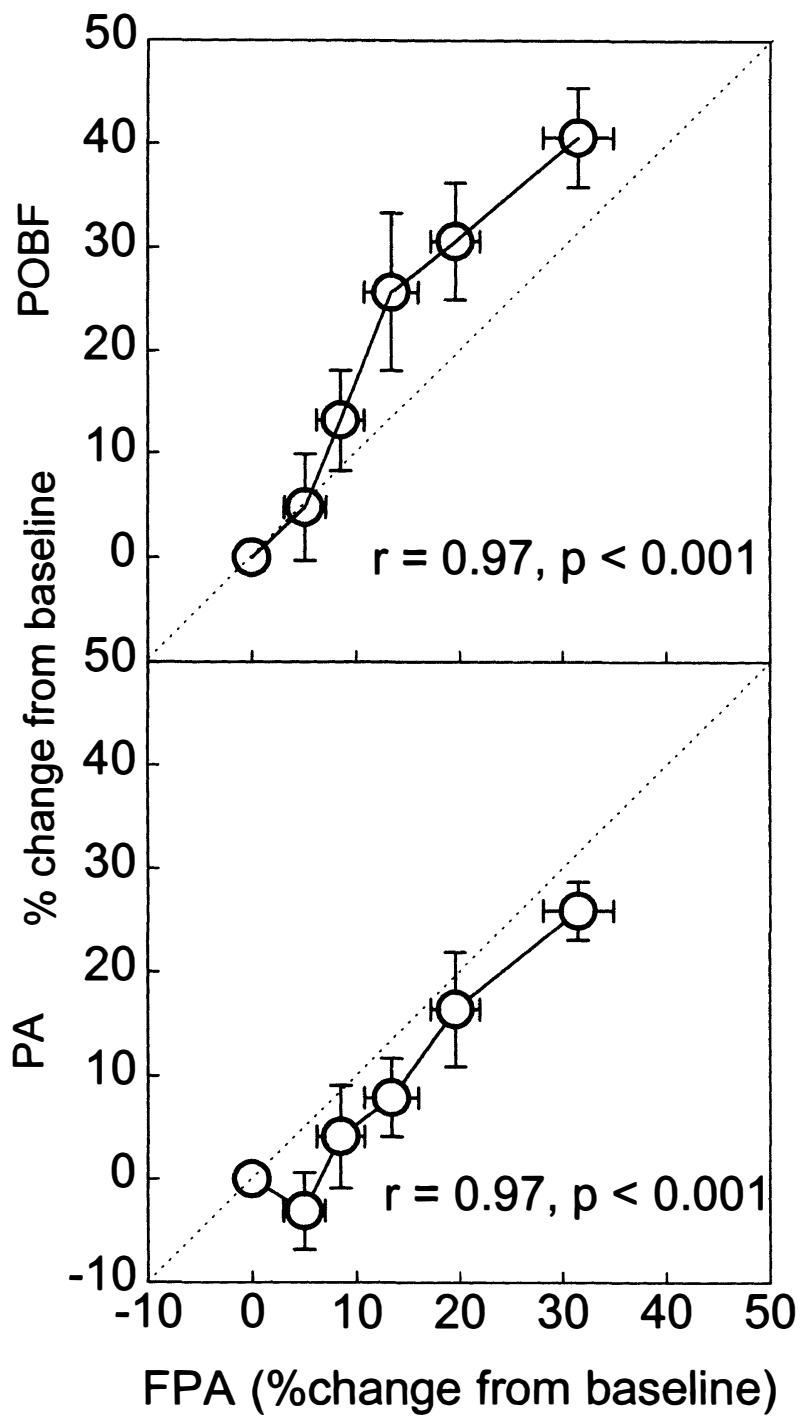

Fig. 2. Linear correlation $(\mathrm{n}=8)$ between changes (mean $\pm S E M)$ during stepwise increasing doses of isoproterenol in fundus pulsation amplitude (FPA) and the pulse amplitude (PA, lower panel) and fundus pulsation amplitude (FPA) and pulsatile ocular blood flow (POBF, upper panel)

than the $45^{\circ}$ line $(p=0.028)$. We also observed a strong association between isoproterenol-induced changes in FPAC and PA or POBF (Fig. 3; \%change in POBF $=1.21$ $+0.92 \times \%$ change in FPAC; \%change in PA $=-3.68$ $+0.63 \times \%$ change in FPAC). Whereas the slope of the regression line between isoproterenol-induced changes in FPAC and POBF was not significantly different from 1.0, the regression line between changes in FPAC and PA was again flatter than the $45^{\circ}$ line $(p=0.004)$. Isoproterenol dose-dependently increased SBP from $120 \pm 13 \mathrm{mmHg}$ to $133 \pm 9 \mathrm{mmHg}$ at the highest dose $(p=0.001)$. The effects on DBP $(66 \pm 8 \mathrm{mmHg}$ at baseline, $60 \pm 9 \mathrm{mmHg}$ at the highest dose) and MAP

( $84 \pm 8 \mathrm{mmHg}$ at baseline, $86 \pm 12 \mathrm{mmHg}$ at the highest dose) were not significant. PPA increased dose dependently ( $p=0.002$ ) from $55 \pm 12 \mathrm{mmHg}$ to $69 \pm 25 \mathrm{mmHg}$. Isoproterenol also exerted a significant increase in pulse rate (from $69 \pm 6 \mathrm{~min}^{-1}$ at baseline to $78 \pm 6 \mathrm{~min}^{-1}$ at the highest dose, $\left.p<0.001\right)$.

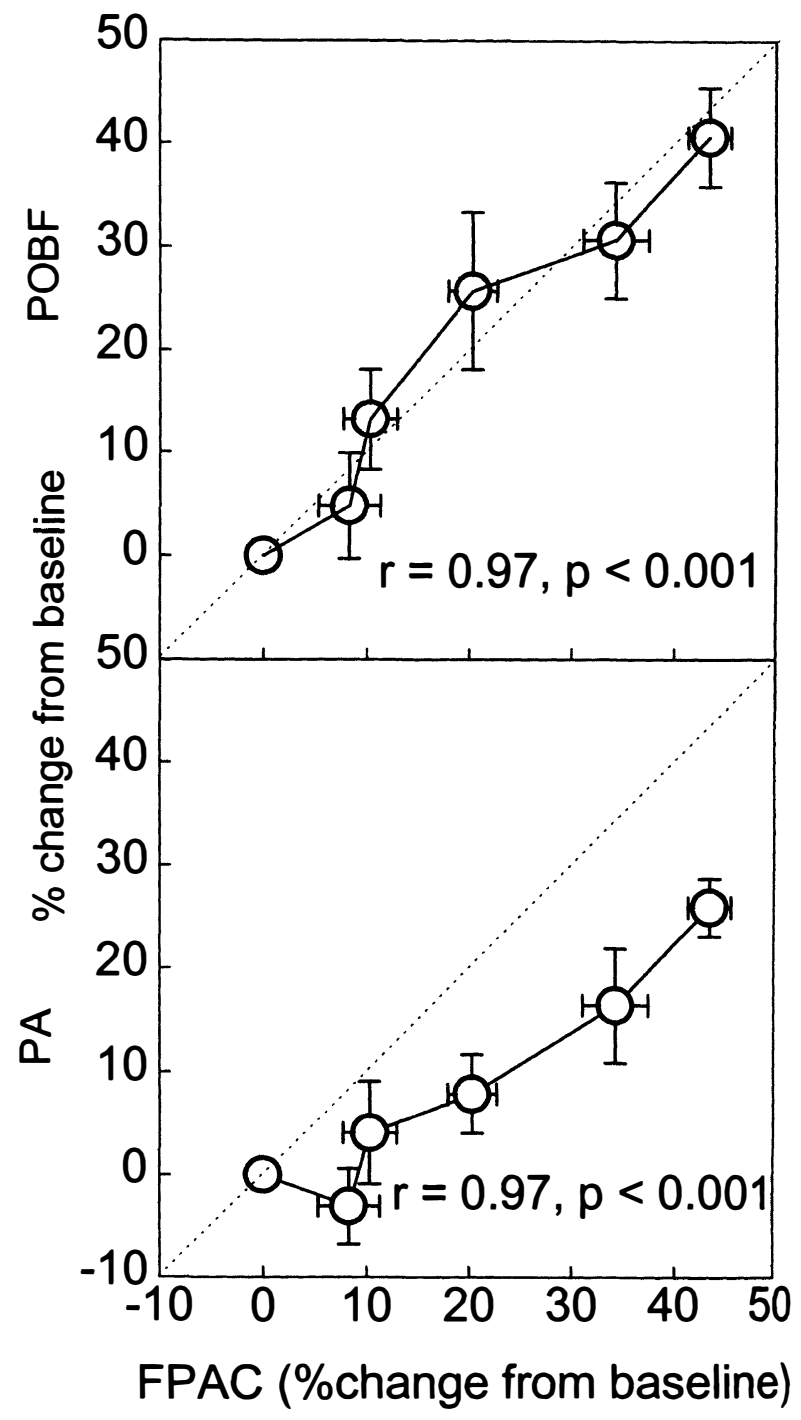

Fig. 3. Linear correlation $(\mathrm{n}=8)$ between changes (mean $\pm S E M)$ during stepwise increasing doses of isoproterenol in corrected fundus pulsation amplitude (FPAC) and the pulse amplitude (PA, lower panel) and corrected fundus pulsation amplitude (FPAC) and pulsatile ocular blood flow (POBF, upper panel).

\section{Discussion}

\section{Effects of high $\mathrm{pCO}_{2}$}

It is well established that the retinal ${ }^{7-9}$ and the choroidal $^{4,5,7,10-12}$ circulation show a high reactivity to changes in $\mathrm{pCO}_{2}$. The observed increase in FPA, PA and POBF during hypercapnia in the present study corroborates these previous findings in the choroid. The FPA response to hypercapnia was observed at five different measurement sites, which argues that at least near the macula the hypercapnic response does not show a wide local variability (Table 1 ).

Interestingly, one subject showed almost no ocular haemodynamic response to hypercapnia (Fig. 1). This was evidenced by both laser interferometry and pneumotonometry. However, it must be kept in mind that both methods assess only the pulsatile component of ocular blood flow and it cannot be excluded that there was an increase in the steady flow component in this subject. Based on our results we cannot judge whether 
inhalation of $5 \% \mathrm{CO}_{2}+95 \%$ air produced a significant change in flow pulsatility, but no change in systemic blood pressure profile was induced by hypercapnia.

A high degree of association between hypercapniainduced changes in FPA and pneumotonometric parameters was observed. Due to the small number of subjects under study the correlation between FPA and POBF did not reach the level of significance. Nonetheless, our results argue that laser interferometry as well as pneumotonometry are capable of characterising effects of changes on $\mathrm{pCO}_{2}$ on pulsatile choroidal blood flow.

\section{Effects of high $\mathrm{pO}_{2}$}

Retinal blood flow shows a high reactivity to changes in $\mathrm{pO}_{2} \cdot{ }^{13-16}$ In contrast, the reactivity of choroidal blood flow to hyperoxia is small. ${ }^{4,5,10-12}$ In the present study we observed a small but significant decrease in FPA, but no change in PA or POBF, during hyperoxia, although we increased $\mathrm{pO}_{2}$ almost 5-fold. The fact that $100 \% \mathrm{O}_{2}$ breathing produced a significant change in FPA, but not in POBF or PA, could simply be explained by the better reproducibility of laser interferometric as compared with pneumotonometric measurements. ${ }^{17,18}$ An alternative explanation is that pneumotonometry provides a measure of global pulsatile blood flow, whereas FPA is focal in nature. Whereas we consistently found a small decrease in FPA during hyperoxia, ${ }^{4,5}$ previous studies did not observe any reactivity of the choroid. ${ }^{10-12}$ The better reproducibility of the FPA measurements as compared with most other methods, as well as a shift from pulsatile to non-pulsatile blood flow during hyperoxia, could account for this discrepancy.

The hyperoxic response of FPA in the optic disc was greater than that in the macula, which is in keeping with our previous findings. ${ }^{4,5}$ We have speculated previously that in the optic disc both retinal and choroidal blood flow contribute to FPA, as the optic disc vasculature is supplied by both the central retinal artery and the posterior ciliary arteries. ${ }^{19}$

A decrease in optic nerve blood flow during hyperoxia has also been observed with laser Doppler flowmetry. ${ }^{20}$ In contrast to our results, Riva and co-workers ${ }^{20}$ observed a higher reactivity at the neuroretinal rim than on the cup. However, it must be emphasised that laser Doppler flowmetry assesses blood flow in the capillary layers of the optic nerve and that the results are therefore not directly comparable.

\section{Effects of isoproterenol}

We have shown previously that isoproterenol increases FPA in a dose-dependent fashion. ${ }^{3,21}$ This increase in FPA is mainly caused by the increase in systemic PPA, which is the driving force of pulsatile blood flow, ${ }^{21}$ although a direct $\beta$-receptor-dependent vasodilation in the choroid cannot be excluded. ${ }^{22,23}$ In the present study the increase in pulsatile choroidal blood flow during isoproterenol administration was evidenced from the increase in FPA, PA and POBF.
The association between isoproterenol-induced changes in FPA and pneumotonometric parameters was high. Whereas the correlation line between changes in FPA and PA almost matched the $45^{\circ}$ line, the correlation line between FPA and POBF was considerably steeper.

The FPA corrected for changes in pulse rate (FPAC) also showed a strong correlation with pneumotonometric parameters. Moreover, the correlation line between FPAC and POBF almost matched the $45^{\circ}$ line, which argues that the discrepancies between POBF and FPA in describing ocular haemodynamic changes in response to isoproterenol are indeed caused by concomitant changes in pulse rate.

It must be emphasised that during isoproterenol administration neither pneumotonometric nor laser interferometric parameters can be used to describe changes in total ocular blood flow, if no additional information on flow pulsatility is available. Whereas PPA was increased during isoproterenol, DBP tended to decrease, which most likely increased flow pulsatility in the ocular vasculature. We have described this limitation of methods for the assessment of pulsatile ocular blood flow previously. ${ }^{24,25}$

\section{Conclusions}

The present study shows that there is a high association between laser interferometric and pneumotonometric parameters in characterising changes in the pulsatile component of ocular blood flow as induced by high $\mathrm{pCO}_{2}, \mathrm{pO}_{2}$ and isoproterenol. This argues that FPA can be taken as a valid relative measure of pulsatile choroidal blood flow. In cases when significant changes in pulse rate are expected, FPA should be corrected accordingly. Moreover, our results indicate that FPA in the optic disc is influenced by both retinal and choroidal circulation. The contribution of the retinal circulation may be stronger in the cup than at the neuroretinal rim.

The authors are indebted to Chris Crowhurst and David Massey from OBF Labs (UK) Ltd for the loan of the OBF system.

\section{References}

1. Kiel JW. Choroidal myogenic autoregulation and intraocular pressure. Exp Eye Res 1994;58:529-44.

2. Schmetterer L, Lexer F, Unfried C, Sattmann H, Fercher AF. Topical measurement of fundus pulsations. Opt Eng 1995;34:711-6.

3. Schmetterer L, Wolzt M, Salomon A, Rheinberger A, Unfried C, Zanaschka G, et al. The effect of isoproterenol, phenylephrine and sodium nitroprusside on fundus pulsations in healthy volunteers. Br J Ophthalmol 1996;80:217-23.

4. Schmetterer L, Wolzt M, Lexer F, Alschinger C, Gouya G, Zanaschka G, et al. The effect of hyperoxia and hypercapnia on fundus pulsations in the macular and the optic disc region. Exp Eye Res.1995;61:685-90.

5. Schmetterer L, Lexer F, Graselli U, Findl O, Eichler HG, Wolzt M. The effect of different mixtures of $\mathrm{O}_{2}$ and $\mathrm{CO}_{2}$ on ocular fundus pulsations. Exp Eye Res 1996;63:351-5. 
6. Schmetterer L, Dallinger S, Findl O, Strenn K, Lexer F, Eichler HG, et al. A comparison between laser interferometric measurement of fundus pulsation and pneumotonometric measurement of pulsatile ocular blood flow. 1. Baseline considerations. Eye 2000;14:39-45.

7. Alm A, Bill A. The oxygen supply to the retina. II. Effects of high intraocular pressure and of increased arterial carbon dioxide tension in uveal and retinal blood flow in cats. Acta Physiol Scand 1972;84:306-19.

8. Tsacopoulos M, David NJ. The effect of arterial $\mathrm{pCO}_{2}$ on relative retinal blood flow in monkeys. Invest Ophthalmol 1973;12:335-47.

9. Harris A, Arend O, Wolf S, Cantor LB, Martin B. $\mathrm{CO}_{2}$ dependence of retinal arterial and capillary blood velocity. Acta Ophthalmol 1995;73:421-4.

10. Friedman E, Chandra SR. Choroidal blood flow. III. Effects of oxygen and carbon dioxide. Arch Ophthalmol 1972;87:70-1.

11. Riva CE, Cranstoun SD, Grunwald JE, Petrig BL. Choroidal blood flow in the foveal region of the human ocular fundus. Invest Ophthalmol Vis Sci 1994;35:4273-81.

12. Riva CE, Petrig BL. Choroidal blood flow by laser Doppler flowmetry. Opt Eng 1995;34:746-52.

13. Riva CE, Grunwald JE, Sinclair SH. Laser Doppler velocimetry study of the effect of pure oxygen breathing on retinal blood flow. Invest Ophthalmol Vis Sci 1983;24:47-51.

14. Grunwald JE, Riva CE, Petrig BL, Sinclair SH, Brucker AJ. Effect of pure $\mathrm{O}_{2}$-breathing on retinal blood flow in normals and in patients with background diabetic retinopathy. Curr Eye Res 1984;3:239-41.

15. Langhans M, Michelson G, Groh MJM. Effects of breathing $100 \%$ oxygen on retinal and optic nerve head capillary blood flow in smokers and non-smokers. Br J Ophthalmol 1997;81:355-9.
16. Strenn K, Menapace R, Rainer G, Findl O, Wolzt M, Schmetterer L. Reproducibility and sensitivity of scanning laser Doppler flowmetry during graded changes in $\mathrm{pO}_{2}$. $\mathrm{Br} \mathrm{J}$ Ophthalmol 1997;81:360-4.

17. Butt Z, O'Brien C. Reproducibility of pulsatile ocular blood flow measurements. J Glaucoma 1995;4:214-8.

18. Schmetterer L, Dallinger S, Findl O, Strenn K, Graselli U, Eichler HG, et al. Noninvasive investigations of the normal ocular circulation. Invest Ophthalmol Vis Sci 1998;39:1210-20.

19. Hayreh SS. The optic nerve head circulation in health and disease. Exp Eye Res 1995;61:259-72.

20. Riva CE, Harino S, Petrig BL, Shonat RD. Laser Doppler flowmetry in the optic nerve. Exp Eye Res 1992;55:499-506.

21. Schmetterer L, Findl O, Strenn K, Fasching P, Zanaschka G, Eichler HG, et al. Ocular and systemic reactivity to isoprenaline in patients with insulin-dependent diabetes mellitus. Eur J Clin Invest 1997;27:750-4.

22. Bruninink A, Dawis S, Niemeyer G, Lichtensteiger W. Catecholaminergic binding sites in cat retina, pigment epithelium and choroid. Exp Eye Res 1986;43:147-51.

23. Grajewski A, Ferrari-Dileo G, Feuer W, Anderson D. Beta adrenergic responsiveness of choroidal vasculature. Ophthalmology 1991;98:989-95.

24. Krejcy K, Wolzt M, Kreuzer C, Breiteneder H, Schütz W, Eichler HG, et al. Characterisation of angiotensin II effects on cerebral and ocular circulation by noninvasive methods. Br J Clin Pharmacol 1997;43:501-8.

25. Matulla B, Streit G, Pieh S, Findl O, Entlicher J, Graselli U, et al. Effects of losartan on cerebral and ocular circulation in healthy subjects. Br J Clin Pharmacol 1997;44:369-75. 